\title{
Service Systems in Changing Paradigms: An Inquiry through the Systems Sciences
}

David Ing

Forthcoming in The Science of Service Systems (Haluk Demirkan, James C. Spohrer and VikasKrishna, editors), in the Service Science: Research and Innovations (SRII) in the Service Economy book series, Springer 2010.

This manuscript was posted on the Coevolving Innovation website at http://coevolving.com/commons , in February 2010, in advance of publication in the edited volume. The chapter was accepted by the book editors in January 2010, in response to the call at http://www.public.asu.edu/ hdemirka/index_files/CFC_SS_Books_Springer.htm . 
The Science of Service Systems

\title{
Service Systems in Changing Paradigms: An Inquiry through the Systems Sciences
}

David Ing1, IBM Canada Ltd.; and Aalto University, Department of Industrial

Engineering and Management

\begin{abstract}
For professionals at the beginning of the 21st century, much of the conventional wisdom on business management and engineering is founded in the 20th century industrial / manufacturing paradigm. In developed economies, however, the service sector now dominates the manufacturing sector, just as manufacturing prevailed over the agricultural sector after the industrial revolution.
\end{abstract}

This chapter proposes the development of a body of knowledge on services systems, based on foundations in the systems sciences. The approach includes the design of the systems of inquiry, acknowledging that body of knowledge on $21^{\text {st }}$ century service systems is relatively nascent. A program of action science is proposed, with an emphasis on multiple realities and knowledge development through dialectic. The outcome pursued is an increased number of T-shaped people with depth and breadth in service systems, in communities of inquiry of researchers and practitioners.

Keywords: service systems, service science, inquiring system, action science, paradigms

\section{Introduction: Structural changes in the world economy call for an inquiry into the understanding of service systems amongst scientists, managers, engineers and designers}

Conceptually, services are not new. Concretely, an encounter with an instance of a service system is an everyday event. One can be recognized by its structure (e.g. resource configurations), function (e.g. creation and delivery of value) and process (e.g. party-to-party coordination):

A service system can be defined as a dynamic configuration of resources (people, technology, organisations and shared information) that creates and delivers value between the provider and the customer through service. In many cases, a service system is a complex system in that configurations of resources interact in a non-linear way. Primary interactions take place at the interface between the provider and the customer. However, with the advent of ICT, customer-to-customer and supplier-to-supplier interactions have also become prevalent. These complex interactions create a system whose behaviour is difficult to explain and predict. (IfM and IBM 2008, p. 6)

\footnotetext{
${ }^{1}$ Corresponding Author - daviding@ca.ibm.com
} 
Abstracting beyond instances of services to obtain a generalized understanding across a variety of types of service systems is a challenge. Changes in society, technology and economics have brought new voices to the prior conventional wisdom on services. Conceptual definitions, common features and principles from a systems foundation are yet to be fully worked out.

... a theory of service systems should explain what service systems are and aren't, how they arise and evolve, the relation between internal and external service systems, and the role of people, technology, value propositions, and shared information in the system. (Spohrer Maglio et al. 2007, p. 73)

In the interest of developing a general theory, service systems should be acknowledged as subtypes of systems. It then follows than an emerging science of service systems is a specialization of the science of systems.

Systems science (including cybernetics) is not a traditional discipline concerned with the study of a particular domain, but a meta-discipline, concerned with the domain-independent modelling of general systems (Van Gigch 1986). As such, it does not aim to find the one true representation for a given type of systems (e.g. physical, chemical or biological systems), but to formulate general principles about how different representations of different systems can be constructed so as to be effective in problem-solving. (Heylighen 1990)

Service systems are currently regarded as a multi-discipline within science, and may or may not mature into a meta-discipline.

Despite the rise of the services economy into the 21st century, "few researchers have studied service, and institutions have paid little attention to educating students in this area" (Spohrer Maglio et al. 2007). This chapter aims to contribute to coherency in the body of knowledge amongst scientists, managers, engineers and designers by inquiring into the underlying ways of knowing, i.e. inquiring systems. The next three subsections outline the challenge, an approach, and the desired future.

1.1 Challenge: Our prior understanding of service systems is inadequate for societal challenges that we foresee in the $21^{\text {st }}$ century

The future is already here. It's just not very evenly distributed. (William Gibson)

A National Academy of Engineering report has been interpreted as a "failing grade for the innovation academy" for not meeting the needs of service businesses (Chesbrough 2004). The impact of ICT (Information and Communications Technologies) on growth and labour productivity was concentrated in the services sector and a few manufacturing sectors (OECD 2000), and significant in all 20 OECD countries in the period between 1995 and 2005 (OECD 2007). Yet, a business school professor exclaimed "Why is it that 80 percent of the economy in the United States is service yet 80 percent of the required operations management courses in business schools still focus primarily on manufacturing?” (Davis and Berdrow 2008).

Existing theories are clustered in schools of management, science and engineering, social sciences and humanities, and information. Advances in research into service systems are hampered by specialization along disciplinary lines, reinforced by expectations from institutions and funding bodies that work against an integrated ap- 
proach. A skill gap has resulted as university graduates have insufficient training to work on innovating and interdisciplinary activities (IfM and IBM 2008).

Section 2 of this chapter will frame the development of a science of service systems as a paradigm shift. While meaning is occasionally shared across scientists, engineers, managers and designers, disciplinary thinking is a more common pattern. To see the boundaries on knowledge more clearly, five ways of knowing - inquiring systems - are outlined. Learning - both for researchers and practitioners - follows in a proposed program of action science.

\subsection{Approach: Developing the coherency and validity of a science of service systems requires engagement with multiple realities, and new syntheses produced through dialectic}

A large body of knowledge on services already exists. The challenge is how to integrate and/or bridge perspectives into a systemic whole. This presents an unbounded, unstructured problem, in which knowledge has already been structured within bounds.

... with few exceptions, professional schools largely teach their students how to solve bounded-structured problems. (....) The problem is "structured" in that it is phrased unambiguously in a language ... that states clearly what the problem is, and gives an equally clear procedure for finding the solution ... Just as strongly, there is a clear sense of what constitutes a "solution". The problem is "bounded" in that there is a finite set of appropriate "solutions" to the initial problem. (....)

Unbounded problems, on the other hand, are generally on the cutting edge of knowledge. In the early stages of research, there may well be no single, accepted way of posing or structuring a problem to the satisfaction of all experts. (Mitroff and Linstone 1993, p. 14)

In particular, the compartmentalization of universities is criticized in three splits: (a) the theory-action split, (b) the peer-society split, and (c) the teacher-student split. In the theory-action split, scientists are cut off from learning possibilities involved with testing theories in praxis. In the peer-society split, the important research questions that cross professional boundaries are inhibited. In the teacher-student split, professors are discouraged from engaging in mutual learning activities with students and extra-academic stakeholders by distancing themselves (Levin and Greenwood 2001).

The development of new body of knowledge in service systems can be approached, in an alternative to a positivist science, as action science. Researchers and practitioners would advance theories in practice.

Action science assumes that human beings are theory-builders who mentally 'construct' theories of reality, which they continually test through action (Argyis and Schön 1974; ... Senge 1990). The difference between researchers and practitioners is that the former are 'explicit' theoreticians whereas the latter are 'tacit' theoreticians. The objective of action science is to make these tacit theories explicit so that they can be critically examined and changed. (Friedman 2001, p. 161)

Accordingly, this chapter is based largely on inductive and abductive reasoning, rather than deduction (Ing 2009). 
Section 3 of this chapter introduces concepts from the systems sciences as a way to shape the multiple realities that emerge from a science of service systems crossing disciplinary boundaries.

Section 4 of this chapter opens the opportunity for dialectic by abducing a position through which knowledge might be generated through dialogue. Since this written content represents only one side of a dialectic, the written word is incomplete, and new knowledge will not be generated until multiple parties engage in joint sensemaking through rich conversations.

1.3 Desired future: T-shaped people should have not only a depth in a domain of service systems, but also an appreciation of the breadth of related service systems designs

Developing a science of service systems is not an end in itself. The function of a stronger understanding of service systems is a capacity to gain insights into a design or situation at hand, drawing on theories from general or related service systems. Redesigning a service system requires deeper knowledge than maintaining an existing one. The goal is typically to improve or transform from a current (functional or dysfunctional) state to some desired future state.

Section 5 of this chapter foreshadows an opportunity for a variety of professions scientists, engineers, managers and designers - to cooperate in a shared body of knowledge. Progress on this cooperation relies much on a mutual understanding of concepts and language, as well as the recognition that errors and unknown knowns (as passive ignorance, ignoring) and taboos and denials (as active ignorance, the ignored) from industrial age thinking may be surfaced (Ing, Takala and Simmonds 2003). Educational programs on service systems in the spirit of action science are exceptions rather than the rule.

\section{As paradigms on service systems shift, alternative inquiring systems support learning through a program of action science}

“It's like the fish in water. We don't know who discovered water but we know it wasn't a fish. A pervasive medium is always beyond perception.” - Marshall McLuhan

Establishing doxa in engineering and management while a new science of service systems emerges draws attention to a legacy in science. Current practices, experience and education are anchored in disciplines with a long history of development over the past half century. The predispositions and assumptions from the last half century may or may not continue to be valid in the next half century. As a practical example, how should business performance of service system be measured? Many service businesses count hours of labour (e.g. billable utilization) as a key measure of productivity. When revenue and profitability are driven by the application of expertise and skills, the logic of tracking hours can encourage dysfunctional behaviours. Client satisfaction and the quality of customer deliverables are not always improved by more working hours. As a corollary, counting hours worked and not worked (e.g. vacation) induces an administrative overhead unnecessary for senior 
business professionals who are otherwise trusted to meet planned business commitments (Belson 2007). Counting hours in a service business may be as nonsensical as a standard 9-to-5 schedule to a farmer who tends to fields and livestock from sunrise to sunset.

In the subsection that follows, the challenge of clearly seeing services systems in the "new" economy with mindsets from the "old" economy are reviewed. Advances in technology are posed as a primary driver changing economics in businesses and society. Then, the systems sciences are proposed as common points of reference for both engineering and management education. Outlining the variety of inquiring systems surfaces closed and open ways of knowing. Action science is then described a method through which group learning can be conducted.

\subsection{The science of service systems is immature, catching up with $21^{\text {st }}$ century technological, economic and social changes}

Does the development of a science of service systems represent a new paradigm? The science of service systems has yet achieved the status of a normal science, from which features of scientific practice (e.g. law, theory, application and instrumentation) provide coherent models (Kuhn 1967/1996). Some parts of the science of service systems could be described as immature or ineffective, in the resolution of practical problems.

In such an uncontrolled and perhaps uncontrollable context, where facts are few and political passions many, the relevant immature field functions to a great extent as a 'folk-science'.

(....)

The indubitable and public symptom of ineffectiveness of a field is the absence of facts.... (Unlike) in a matured field, the students do not encounter a collection of standardized materials, presented in a digestible form, and utterly reliable and incontrovertible in themselves .... By contrast, in the ineffective or immature field, the student is presented with one out of several sets of supposed basic materials, and can discover other sets by reading textbooks not on the recommended list. These materials themselves consist of intuitive generalized dressed up as empirical laws, and insecure theoretical speculations masquerading as fundamental explanations. (Ravetz 1971, pp. 366-367)

A paradigm is "a mode of viewing the world which underlies the theories and methodologies of science in a particular period of time" (New Shorter Oxford English Dictionary 1997). In a practical evolutionary view, three stages have been proposed as "a nation's economic evolution" - mechanical, electrical, and information (Tien and Berg 2003). This thinking can be extended to recognize advances in science with technology along a non-exhaustive list of disciplines, e.g.

- mechanical,

- biological,

- material/chemical,

- electrical, and

- information / communications.

Within each of these fields of science, paradigms have shifted. In biology, the discovery of DNA led to the advent of molecular biology. In material science, nano- 
technology reveals properties previously unseen at the molecular level. Simultaneously with changes within these sciences, boundaries between disciplines have naturally become redefined (e.g. biology and chemistry have led to biochemistry).

Business opportunities arise as paradigm shifts lead to technologies that change the possibility and feasibility of products and services.

The effect of technology is - and always has been -- to loosen constraints. As a result of technological development, what was not possible becomes possible. Or what was not economically feasible becomes so. (Normann 2001, p. 27)

In the late 1990s, the most significant paradigm shift for the sciences and the business world was in information, as digital content became networked, i.e. the Internet. These advances not only impacted computer science, but also other fields (e.g. bioinformatics in the life sciences). A new conventional wisdom on a science of service systems will take years to work through definitions and distinctions. This new science of service systems is largely being driven inductively from developments of society and business.

2.2 Intelligibility on service systems amongst scientists, managers, engineers and designers can be enabled through foundations in the systems sciences

The motivation to view service systems through a lens of systems science is practical. In the services specialization of systems, definitions and theories are still evolving. At this time, systemics - as "an open set of concepts, models and practical tools useful for a better understanding and eventual management of complex situations or entities of any type" (François 1997, p. 362) - enable a rich vocabulary and set of concepts for discussion.

System science has a tradition of linkages with engineering, management and design. Systems engineering applies principles from systems science to improve performance and efficiency. In management, concepts and vocabulary from approaches such as the socio-technical systems perspective - rooted in human systems research at the Tavistock Institute (Trist et al. 2003) - is so deeply embedded in organization theory as to have become invisible. The pursuit of business and social innovation emphasizing creativity in systems design has been exhibited in formation of crossdisciplinary D-Schools (Atal and Woyke 2007).

The engineering of service systems conceptually would seem to be a small step from systems engineering. The IEEE defines systems engineering as "an interdisciplinary collaborative approach to derive, evolve, and verify a life-cycle balanced system solution which satisfies customer expectations and meets public acceptability". An alternative concise definition sees systems engineering as "a multidiscipline that addresses a system from a life-cycle, cybernetic and customer perspective” (Tien and Berg 2003, pp. 22-23). Although some would perceive engineering as based primarily in hard science, the systems engineering literature includes natural and human sciences as part of the domain:

(A) system (can be defined as) an assemblage of objects united by some form of regular interaction or interdependence ... A system can be natural (e.g., lake) or built (e.g., government), physical (e.g., space shuttle) or conceptual (e.g., plan), closed (e.g., chemicals in a stationary, closed bottle) or open (e.g., tree), static (e.g., bridge) or dynamic (e.g., 
human). In regard to its elements, a system can be detailed in terms of its components, composed of people, processes and products; its attributes, composed of the input, process and output characteristics of each component; and its relationships, composed of interactions between components and characteristics. (Tien and Berg, 2003, pp. 23-24)

The lineage of engineering as an applied science following from theoretical knowledge is obvious.

The management of service businesses requires some reframing from the heritage of industrial businesses. Management - in itself, a multidiscipline - has hidden foundations from some leading thinkers who encourage a systems approach. While some see management as an art, others emphasize the science in management.

(Amongst) Management Scientists ... the systems approach to problems is fundamental and ... organizations, a special type of system, are the principal subject of study.

The systems approach to problems focuses on systems taken as a whole, not on their parts taken separately. Such an approach is concerned with total-system performance even when a change in only one or a few of its parts is contemplated because there are some properties of systems that can only be treated adequately from a holistic point of view. These properties derive from the relationship between parts of systems: how the parts interact and fit together. (Ackoff 1999/1974)

There is not a single systems approach in management. Generic methodologies have been constructed for a functionalist systems approach (with 7 categories of theories), an interpretative systems approach (with 7 categories of theories), an emancipatory systems approach (with 2 categories of work) and a postmodern systems approach, leading to development of a pluralist approach of critical systems thinking (Jackson 2000).

The design of service systems integrates human systems with technical systems. In the industrial age, the pace at which machines were upgraded or replaced was measured in years, if not in decades. The advent of software has accelerated the pace of change with fixes, patches and upgrades into hours, if not minutes. The recognition of service systems with varying levels of information intensity has recently surfaced the consideration of alternative contexts for design (Glushko 2010).

While depth in at least one of the professions - science, engineering, management or design - provides a perspective on which knowledge on services systems could be advanced more generally, ambiguity in the breadth and bounds of the systems sciences themselves are considered to be a strength. Systemicists largely agree that systems science loses its value if it is seen as a discipline.

Systems science is a meta- or trans-discipline (or possibly better, a meta-methodology) for everybody, and should not be simply reduced to a discipline status, even when and where it must be teached (sic). (François 1997, p. 362)

For the interests we have at hand - bridging the language and concepts of scientists, engineers, managers and designers, so that discussions of analysis and design can productivity proceed - systems concepts and languages can aid in clarity. The undesirable alternative would have the quality of discourse fall to the common level of a Grade 6 education. When a $21^{\text {st }}$ century paradigm on service systems has developed sufficiently with a normal science, the systems sciences will then likely recede into the background as a foundational body of knowledge. 


\subsection{The validity of analytic-deductive inquiry and inductive-consensual inquiry can be re-established by sweeping in knowledge through multiple realities and dialectic}

Inquiry is an activity which produces knowledge. (Churchman 1971, p. 8)

In periods of normal science, the world is known through commonsense understanding and coherent frameworks as published in textbooks. Emphasis is placed on dissemination of the known, over the pushing the frontiers of knowledge. In times of revolutionary change - as in scientific revolutions - commonsense understanding and textbooks are of suspect reliability. Knowledge generation rises in importance.

An inquiring system "is a system of interrelated components for producing knowledge on a problem or issue of importance" (Mitroff and Linstone 1993, p. 29). Five designs, based on philosophies developed over the $17^{\text {th }}$ to $20^{\text {th }}$ centuries, have been identified. Although the designs have been described with a variety of labels - see Table 35-1 - we'll refer to the five ways of knowing: (1) inductive-consensual, (2) analytic-deductive, (3) multiple realities, (4) conflict, and (5) unbounded systems thinking.

Table 35-1: Designs of Inquiring Systems

\begin{tabular}{|l|l|l|l|}
\hline $\begin{array}{l}\text { Way of } \\
\text { Knowing }\end{array}$ & Mitroff and Linstone 1993 & Mitroff 1998 & Churchman 1971 \\
\hline First & Inductive-Consensual & Expert Consensus & Locke: consensus \\
\hline Second & Analytic-Deductive & Expert Modeling & Leibniz: fact nets \\
\hline Third & Multiple Realities & Multiple Models & Kant: representations \\
\hline Fourth & Conflict & Conflict & Hegel: dialectic \\
\hline Fifth & Unbounded Systems Thinking & Systemic Reasoning & Singer: progress \\
\hline
\end{tabular}

The first and second ways of knowing are based in objective views of knowledge. The third way of knowing recognizes subjective views, where the model and data are inseparable in the minds of individuals. The fourth way of knowing generates knowledge through debates from polar positions. The fifth way of knowing incorporates aspects of the preceding four ways, with a guarantor of "progress" that ensures more perspectives and views are swept in. (Ing, Takala and Simmonds 2003)

Many of the service systems in our everyday life are understood on the first two "ways of knowing". In the first way of knowing - inductive-consensual - service systems can be often understood by simply observing social behaviour. Public service systems for citizens typically function by showing up in person and queuing (at least in orderly countries), with coordination self-enforced through social norms on taking turns. In the second way of knowing - analytic deductive - service systems can be understood by decoding the formula. Automated services typically ask requesters to choose from a menu, or respond to a series of questions, or invoke an exit option for exceptions.

In the third way of knowing - multiple realities - service systems produce a greater variety of outcomes with the introduction of subjective views. The same service output delivered to two different customers in exactly the same way can be per- 
ceived by each as a different outcome. If the service involves aesthetic judgements either on the part of the customer or of the provider - replicability and consistency can arise as issues. Resolving a customer satisfaction issue using an inductiveconsensual or analytic-deductive design may only serve to further frustrate the client.

In the fourth way of knowing - conflict - service systems require multiple parties for resolution, potentially engaged in either adversarial or constructive positions. In adversarial circumstances, negotiations drawing out hidden assumptions and teasing out preferences and priorities for each stakeholder are often marked by extended deliberations. In constructive circumstances, productive friction can provide the spark for innovation (Hagel and Brown 2005).

The fifth way of knowing - unbounded systems thinking - integrates the other four designs to sweep in new knowledge. Metrology - the science of measurement is central to this inquiring system. If a vector of progress can be established in advance of engagement, dialectic across multiple perspectives continues until advances cease to be obtained. An appropriate metric of performance in educational context could be learning. In a business context, the metric of customer value could be appropriate (Haeckel 1999).

With the science of service systems in its early development, the fifth way of knowing (unbounded systems thinking) is entirely appropriate. This inquiry can be an open system where features of inductive-consensual, analytic-deductive, multiplereality and dialectical thinking are all included, and new ideas are continually swept in. In contrast to viewing disciplines having closed and fixed boundaries (e.g. this idea belongs to economics, that idea belongs to sociology, and the other idea belongs to political science), the friction of distinctions and meanings can lead to production of a distinct new (and unified) perspective on service systems. Establishing the guarantor - the vector of progress by which knowledge generation is to be measured - is the first step.

\subsection{Action science is an appropriate approach for knowledge generation on} service systems in theory and in practice

Service systems include both human systems and technical systems. Between and amongst the actions of recipients and providers of service, social practice (Bourdieu 1977, Dreyfus 1992) and communities of practice (Wenger 1999) introduce complications in descriptive models and normative models. Action science is helpful in untangling some of these distinctions.

(Action science) is an inquiry into social practice, broadly defined, and is interested in producing knowledge in the service of such practice. Thus, what counts as a solution for action science both overlaps with and diverges from prevailing scientific criteria. Like the empirical-analytic tradition, action science requires that knowledge include empirically disconfirmable propositions that can be organized into generalizable theory. But at the same time, it also requires that these propositions be falsifiable in real-life contexts by the practitioners whom they are addressed. Like applied research, action science requires knowledge to be useful. Yet in so doing it emphasizes the designing and implementation of social action, and it rejects the current dichotomy between basic research and applied research. It instead asks that its knowledge illuminate basic issues in ways that are at once generalizable and applicable in particular cases. (Argyris et al. 1985, p. 232) 
Action science is normally conducted by communities of inquiry (within communities of practice). In this early stage of developing a science of service systems, the emphasis should be less on problem solving, and more on problem setting.

Problem solving can be understood as a matter of means-end deliberation. This is because the statement of a well-formed problem includes specification of the purposes to be achieved. But before a problem can be solved, it must be set. (....) Schön writes: "When we set the problem, we select what we will treat as the 'things' of the situation, we set the boundaries of our attention to it, and we impose upon it a coherence which allows us to say what is wrong and in what directions the situation needs to be changed. Problem setting is a process in which, interactively, we name the things to which we will attend and frame the context in which we will attend to them” (1983, p. 40). (Argyris et al. 1985, p. 47)

Section 3 of this chapter describes a series of learning frames, setting up contexts for reflective experimentation, where "participants act, fail, get stuck, and try to get unstuck, while simultaneously reflecting on these attempts with their peers" (Argyris et al. 1985, p. 319). Following action science rules, mutual learning would normally occur in face-to-face situations. Section 4 boldly presents a public inference of a personal inquiry in an interest of evoking responses.

Action science rules ask individuals to retrieve and make public their inferences, while participants' rules lead them to jump to abstract conclusions and to lose sight of the steps that brought them there. Other rules require that participants design valid tests, when their own rules tell them to conduct private tests that create self-sealing processes. And still other rules ask that participants inquire into their errors. (Argyris et al. 1985, p. 320)

Strong responses to these inferences will lend credence to the assertion that the maturity of knowledge on service systems is low, and that opportunities for joint inquiry should continue to be sought.

\section{The coherency of service systems can be examined as multiple realities framed with a variety of systems science concepts}

Towards a goal of learning amongst scientists, engineers, managers and designers, concepts from systems sciences are presented as frames by which assumptions on service systems can be probed. In this interest, ten topics are presented below to guide thinking and discussion about changes in society, economics and technology in the $21^{\text {st }}$ century. The clustering of concepts into ten frames is somewhat arbitrary, and motivated with the practicality of organizing sessions in a series of meetings over a quarter or semester. The ten topics are:

- 1 . Service systems, business models, and value creation

- 2. Ignorance and knowledge

- 3. Boundary

- 4. Order, purpose, self-organization

- 5. Living, being, becoming

- 6. Energy and complexity

- 7. Form, networks and power laws

- 8. Information, communication and meaning 
- 9. Coevolution, competition and variety

- 10. Aesthetics, ethics and morals

If these frames were to be pursued as a study of systems science per se, each frame could become a course by itself. The content and references for each frame follows.

\subsection{Service systems, business models, value creation: Why study service systems?}

The subtlety between service science and a science of service systems draws thinkers into the systems sciences. Why are service systems now so important, when, less than ten years ago, service industries were not considered less desirable sectors of the economy?

While government statistics lag the world by at least a few years, OECD countries have seen services as economic engines towards which resources have recently shifted in a "new" service economy (Wölfl 2005). In the 1990s, information technologies became a major contributor towards increased productivity (OECD 2000). Deeper insight requires analysis of systems within these macroeconomic trends.

As technology has loosened constraints (Normann 2001), shifting opportunities for value creation has driven businesses -- or more generally, institutions formed as purposive social systems - to transform their purposes, functions, structures and processes. Acknowledging a business model as a system design recognizes that individuals and organizations respond to changes in the environment, planned and unplanned.

The business model defines the value-creation priorities of an actor in respect to the utilization of both internal and external resources. It defines how the actor relates with stakeholders, such as actual and potential customers, employees, unions, suppliers, competitors, and other internal groups. It takes account of situations where the actor's activities may

(a) affect the business environment and its own business in ways that create conflicting interests, or impose risks on the actor; or

(b) develop new, previously unpredicted ways of creating value.

The business model is in itself subject to continual review as a response to actual and possible changes in perceived business conditions. (Wallin 2006, p. 12)

Changes towards customer/client/citizen centricity and agility have led monolithic enterprises to transform into value constellations (Ramírez and Wallin 2000), operating in interorganizational networks. These transformations can be informed by recent advances in the study of systems of systems (Jamshidi 2009). In addition to appreciating quid pro quo monetary exchanges in the economy, broadening the perspective to include resources and ethos of social relations and institutions moves opens up the discipline of microeconomics to interactions in economic sociology (Swedberg 2003). 
The Science of Service Systems

\subsection{Ignorance and knowledge: Which aspects of services systems are known, knowable and unknowable?}

As we pursue a science of service systems, what can we know and what should we know? Are there things about the service systems that will (or should) remain unknowable?

A systemic approach to competence development and ignorance (Ing et al. 2003) draws on the training of physicians in the College of Medical Ignorance (Witte et al. 1998). The design of inquiring systems (Mitroff and Linstone 1993; Churchman 1971) sees knowledge generation - essential to development and innovation - as transformative in some situations more than others. While service engineers and service managers may be more comfortable with the knowable, service scientists and service designers may seek out creativity in the unknown and the sacred in an ecology of mind (Bateson 1972).

\subsection{Boundary: Where do we draw lines delimiting service systems from their} environments?

Pure services businesses, manufacturing businesses and agricultural businesses don't really exist. What are the boundaries of a business when viewed as a system? What are the considerations for inclusion or exclusion? How do new informatic spaces (e.g. the Internet) impact social interaction in physical and social spaces?

Understanding service systems as open systems (Katz and Kahn 1978) is foundational. The lenses of physical, social and informatic perspectives are a response to the rise of ICT (information and communication technologies) that have altered the mediating spaces through which social interactions take place (Ing and Simmonds 2002). Principles for designing service systems may be informed by techniques of interactive planning (Ackoff 1994) and pattern languages (Alexander, Ishikawa et al. 1977). The shift to value constellations (Normann and Ramírez 1994) requires adjustments of coordinating action outside of organizational boundaries. In drawing distinctions between parties to be included or served, critical systems theory (Jackson 2000) invokes reflections on boundary judgements.

3.4 Order, purpose and self-organization: Which parts of service systems should be actively designed, and which parts should emerge?

Investments in human systems - with individuals who exercise will - are more prominent in service businesses when compared to manufacturing businesses (with facilities and equipment) and agricultural businesses (with land and cultivation). On which organizational dimensions should leaders of service businesses set direction and/or bounds, and on which should they let direction emerge from the experiences of front-line representatives? Which styles of coordination work in global businesses? What processes enable self-organization?

Unlike machines that operate only on legal (rule-based) order, human systems additionally operate in negotiated order (Strauss 1978) with increasingly distributed network form organizations (Parhankangas, Ing et al. 2005). Organizational systems require different strategies in placid and turbulent environments (Emery and Trist 1965). The horizon for planning goals, objectives and ideals (Ackoff 1981) enables coherency in direction, with context and coordination (Haeckel 1999) additionally 
maintaining consistency. As an alternative to coordinating a service business as did master builders of a cathedral, open source has been compared to a bazaar (Raymond 2000). The scaling of service systems up to global levels can be informed by research into heterarchy (Hedlund 1986), and polycentric and geocentric forms (Permutter and Heenan 1979).

3.5 Living, being, becoming: Can service systems effectively evolve?

As service systems mature, they may continue to prosper as living systems, or decline in relevance to dysfunction and death. Comparing service systems metaphorically to machines or organisms evokes non-rational understandings of change, at the risk of misguidance. Appreciating service systems formally as a subtype of systems in general draws in knowledge on evolution, transformation and pathologies.

The purposes of systems, as a whole and in their parts, can be distinctly categorized as deterministic (mechanistic), animate (organismic), social and ecological models (Ackoff and Gharajedaghi 1996). The essential function of service systems can mapped against the 20 subsystems identified in living systems theory (Miller 1978). Diagnosing dysfunctions through the viable system model (Beer 1972/1981, 1979) sheds light on system dysfunctions through coordination of abstract (e.g. strategic vs. operational) subsystems. Modeling the functional capability for service systems to encode and decode information for metabolism and repair functions itself enables anticipatory behaviour in living systems (Rosen 1985).

\subsection{Energy and complexity: How can service systems be sustainable?}

Natural science sees the world as material, energy and information. Industrial systems typically improve efficiency by embodying repetitive activities into machines. Service systems generally operate with less tangibility and greater agility, often without similar economies of scale. Do service systems have to emulate industrial systems to attain sustainability, or are alternative designs feasible?

In ecosystem ecology, energy and complexity are related through hierarchy theory. Service systems can invest in natural and man-made species of capital as potential energy available to be released on demand.

In economics, the parallelism between energy and capital is related to information (e.g. property rights) in underdeveloped countries (de Soto 2000). The choice between complicated and complexified designs trades off between sustainability and efficiency (Allen et al. 1999). Supply side sustainability explores the advantages and disadvantages of systems operating on high gain resources and low gain resources (Allen et al. 2003). Systems accustomed to high gain resources require a great amount of discipline to transform in a "prosperous way down" to low gain resources (Odum 2007).

A universal property of systems - entropy, the second law of thermodynamics finds that models of economics based on presumptions of equilibrium are misguided (Georgescu-Roegen 1971). As an alternative to bureaucracies of oversight and punitive enforcement, innovations in governance can be introduced through selfregulating designs that dissolve undesired behaviours (Hawk 1999). Mid-level systems can be designed as self-refueling to ensure essential functions are maintain as sustainable in nature (Jacobs 2001). 
3.7 Form, networks and power laws: Over which scales, scopes and speeds can service systems effectively function?

Service systems in the $21^{\text {st }}$ century increasingly operate with parts loosely coupled. Simultaneously, social ties can be developed as long term interorganizational relationships, joint capabilities can be coordinated towards target markets and/or cascaded projects, and each service request can be handled seamlessly with the specific customer, client or citizens at the centre.

Systems theory provides common language and concepts, with structure as an arrangement in space, and process as an arrangement in time. Cellular form organizations (Miles, Snow et al. 1997) are structures well-suited to managing and growing knowledge-intensive service businesses. With research into organization learning only beginning the 1990s, observing "how buildings learn" (Brand 1994) has provided insight into the varying paces of change, with rapidly changing layers shearing against more durable layers. The risk of tightly-coupled systems can lead to "normal accidents" (Perrow 1984).

Service systems designed as networks should not only obey, but also learn to take advantage of power laws (Barabasi 2000). The advent of Internet technologies has enabled the structure of production to be shifted to open source (Benkler 2006). Digitalization also has enabled the potential for products and services to be shifted from the mass market to the long tail (Anderson 2006).

\subsection{Information, communication and meaning: How can service systems be coordinated?}

Small service systems can rely on knowledge embodied in individuals. Larger service systems improve their knowledge and skills by learning, sharing meaning and identity through communities of practice (Wenger 1998).

. In these types of social interaction, information serves a variety of functions (e.g. directing, requesting). Information may be interpreted with different meanings according to the context of the parties to the conversation.

Drawing from computer science, approaching service systems from a language action perspective (Ing 2008), offerings (Ramirez and Wallin 2000) can be coordinated through commitments (Flores and Ludlow 1980). Since service systems include both human systems and technology systems, what computers can and cannot do (Dreyfus 1992) should be appreciated, in the ways that computers effect cognition (Winograd and Flores 1986).

In less directive interactions within service systems, generative conversations (e.g in the style of Béla H. Bánáthy) can dissolve criticisms of overt control. In circumstances of transformation, a context with homeopoetic ethic for organizational change (Rowland 2004) and self-organization of public discourse (Walton 2004) may be appropriate.

\subsection{Coevolution, competition and variety: How can a service system operate in the context of others?}

Leaders of service systems can choose to cooperate, compete or not engage with others. The dimensions of coevolving relationships are complex, each with merits 
and demerits. Competition may or may not result in conflict. Cooperation can be different from coordination, if increased variety is desired. The rise of open source as sharing in communities contrasts to views of private source and ownership.

Definitions of types of interactions between species (e.g. parasitism, mutualism) are categorized in basic ecology (Odum 1983). The benefits of cooperation may show up with positive feedback as increasing returns (Arthur 1996). Within or outside the relationship, coordination may follow the law of requisite variety (Ashby 1956). Benefits may accrue from a design of diversity (Page 2007). If the relationship is not going well, partners may have to choose to express themselves through exit, voice and loyalty (Hirschman 1970). For large scale issues, however, there may be no exit, and action only in the face as catastrophe looms large (Homer-Dixon 2006). Reacting, rather than proactively or interactively dealing with these issues leads only to a post-normal science of precaution (Ravetz 2004).

\subsection{Aesthetic, ethics and morals: What impacts can service systems have on} the human condition?

Service engineers and managers of service businesses may be most explicitly focused in design and economics. From a larger philosophical perspective, there has been a long tradition in the systems movement with the classical ideals of aesthetics, ethics and morals.

The leading view in the systems approach recognizes enemies - politics, morality, religion and aesthetics - with the prescription that they should be embraced (Churchman 1979). In a complementary but different approach, goal setting can be instead considered as values and norms in the appreciative systems of Sir Geoffrey Vickers (Checkland 2005). Both of these approaches have influenced more recent work on systemic governance and creative problem solving through critical systemic praxis (McIntyre 2005). Commercial and guardian syndromes are both recognized as valid systems of survival, with risks of corruption when features are intermixed (Jacobs 1992).

\subsection{Acknowledging systemic frames opens up additional realities on which the coherency of service systems can be examined}

The systems sciences do not provide "right" or "wrong” answers on service systems. They can only provide concepts, language and some principles that can be shared across scientists, engineers, managers and designers.

The science of service systems is not sufficiently mature to provide a standard textbook, based on context that follows deductively. Until the point at which that science has matured, action science suggests learning in communities of inquiry. Each participant in the inquiry will bring his or her own perspective on service systems of interest, surfacing and challenging the assumption of others in engagement. As a foundation, the systems sciences can provide some neutral territory on which sensemaking on service systems can occur. 


\section{The validity of understanding on service systems can be improved through the dialectic of multiple perspectives}

This chapter represents a single perspective on service systems, and is thus inadequate to the task of productively generating new knowledge. The written word does, however, provide an efficient means to potentially provoke a reader to reflect on his or her own frames and assumptions.

The subsection that follows explores the opportunity and challenge of multiple perspectives in developing knowledge in the style of action science. As an exercise for the reader, a single perspective is presented - not as end product, but as a position seeking an opponent to develop even greater knowledge. The reader is invited to challenge, extend or repudiate this position in the interest of advancing a science of service systems.

\subsection{Conversations from multiple perspectives can induce a variety of service system designs}

... to conceive of knowledge as a collection of information seems to rob the concept of all of its life. (....) In other words, knowledge resides in the collection. It is how the user reacts to the collection of information that matters. (Churchman 1971, p. 10)

Only people know. Across the wide variety of types of service systems, each person brings his or her own perspectives, based on personal internal models and experiences. Advancing a science of service systems involves transforming a community of interest - with services at its centre - into a community of inquiry. Crossing prior disciplinary boundaries, that community of inquiry convenes diverse roles to find generalities across - and distinctions between - a range of service systems types. Since the science emerges through social interactions, setting a collegial context is a prerequisite to knowledge development. An ultimate result from the community of inquiry could be new conventional wisdoms about service systems. In a domain where theoretical and practical orientations coincide, however, bridging the variety in communities of practice may be a more practical goal than striving to unify predispositions and perspectives.

As an exercise, the next subsection proposes a position that is theory-building (Eisenhardt and Graeber 2007), with an inductive style that surfaces patterns across a broad range of service systems. This position dissolves the distinctions between the agricultural, manufacturing and service sectors as categorized by economists from an industrial paradigm, in the interest of a more general understanding from a systems perspective. In a dialectic, a practically-oriented position could find parts or the whole of this theory-building perspective irrelevant to an immediate context, or potentially edifying as features from adjacent contexts may be cross-appropriated to improve or transform an existing design.

4.2 A theory-building position on system models in a service economy frames a matrix with types of resources and ethos

Since the $19^{\text {th }}$ century, economists have developed a sense of services as a third sector, the residual after agriculture and industrial production have been taken into 
account. Principles of systems theory lead us to ask about the input, process and outputs associated with human beings working together collectively. A mechanistic worldview sees resources primarily as land, labour and capital - where capital in the industrial age has generally been regarded as machinery driven by internal combustion or electrical motors - and outputs as mostly tangible products.

As system inputs, research into services in the late $20^{\text {th }}$ century has recognized the contribution of knowledge and human skills, e.g. the emergence of a creative class (Florida 2002). As system outputs, research into services recognizes outcomes, e.g. customer satisfaction, as distinct from outputs, e.g. the delivery of the service only from the provider's perspective. As system processes, the model of producerproduct in well-established and replicable formulas has been contrasted with coproduction where outcomes and outputs emerge through synergy (Ackoff and Emery 1972; Normann and Ramirez 1994; Parhankangas, Ing et al. 2005).

In a human-oriented view of service systems, the contribution and involvement of individual and groups particularly impacts mental models. As a position - a starting point into a conversation, and not the end point after deliberation - three categories of resources with three categories of ethos are proposed. When the three categories of resources are mapped against the three categories of ethos, a matrix of nine types of system models is formed.

4.2.1 System inputs acknowledging services include natural and social features of resources

Following the shifts towards a service economy, let's consider three major types of resources:

- (1) renewable resources,

- (2) appropriable resources, and

- (3) cultural resources.

Renewable resources are replenished by nature. Human beings can offset the depletion of renewable resources consumed through programs of replenishment or conservation. Businesses based in renewable resources include farming and fishing. Major activities within such businesses include cultivation and harvesting.

Appropriable resources are generally non-renewable. Manufacturing processes transform the appropriable resources with energy, resulting in man-made products. Businesses based in appropriable resources include extractive activities such as mining and petrochemical refining, and manufacturing activities such as building automobiles. Major activities within these businesses include acquisition and processing.

Cultural resources originate from human interaction. They are embodied in human beings and shared in practices of everyday life. Cultures include language, artistic expressions, rituals and behavioural norms. Cultural practices are reproduced with shared experiences and predispositions through family ties, social networks, history and institutions. In today's world, human beings may adopt aspects of cul- 
ture from regional domiciles, workplaces, generational cohorts and/or shared interests. Participating in these businesses includes affiliating with the culture (e.g. being accepted as legitimate by the community) and practicing the skills (e.g. being a player rather than an observer).

Describing a business by its essential resources is only a partial analysis. As a renewal resource, it's different to grow vegetable on a farm from growing them in a hydroponic skyscraper. The mass production of automobiles is different from an restoration of an antique car. Shooting a major motion picture is different from capturing home videos. This leads to another dimension: ethos.

4.2.2 System processes and outputs acknowledging services include human engagement in practices

An ethos is "the characteristic spirit of a culture, era, community, institution, etc., as manifested in its attitudes, aspirations, customs, etc." (New Shorter Oxford English Dictionary 1997). A business is a social system, so there are varied and alternative structures of actions to produce similar types of outputs. From a systems perspective, ethos is part of the operation of the system. Let's consider three types of ethos:

- (a) an organic ethos,

- (b) an industrial ethos, and

- (c) a service ethos.

The feeling from each ethos comes through from the engagement of an individual associated with a profession or community.

An organic ethos may be described as one that appreciates and nurtures the local bounty. An Amish farm may be the ultimate reflection of an organic ethos in agriculture.

What is underway on an Amish farm does not involve single purpose. The farms are not regarded as economic units, although the Amish make sound economic decisions. What we observe on the Amish farms is similar to what we observe on a natural ecosystem homeostasis. Purpose and mechanism are transcended.

.... (The Amish) are interested in profit and high yield, but neither concern drives them as a single purpose. Had the Land Institute's newly acquired 160 acres been an Amish farm, it would have been highly diversified ... The living riparian community on each side of the two streams would have been a habitat for an abundance of wild species, including quail, pheasant and deer. It would have been a source of fuel, a boundary dividing the farm into smaller fields. It would host some predatory birds and insects. The smaller fields would have suited a horse- or mule-powered agriculture. The larger cottonwoods would have provided shade for grazing animals or for a resting team and driver. The fallen hackberry limb would have been converted into firewood. The straw that we plow under or burn would have would have become bedding for livestock and thus become a way of holding urine and manure, and all three would have returned to the fields from which they came. Some of the grain would be fed on the farm, some would be sold, depending on need.

Because the emphasis for the Amish is not exclusively on production, mass production of food on the farm is incompatible with their sense of how to live in the world. (Jackson 1987, pp. 128-129) 
The description of an organic ethos in the context of business isn't necessarily meant as an anti-technology bias; it is meant as a way seems more natural to the community. Similarly, photography on film holds an organic ethos for those from an age of chemistry in a way that digital photography does not.

An industrial ethos is associated with efficient machinery, and describes much of the modern world. Machines extend the capabilities of human beings, replacing social functions with automated mechanisms -- either as improvements or degradations, depending on the point of view. Much of the business world implicitly takes the industrial ethos, from the days of Henry Ford's Model T, to the current day.

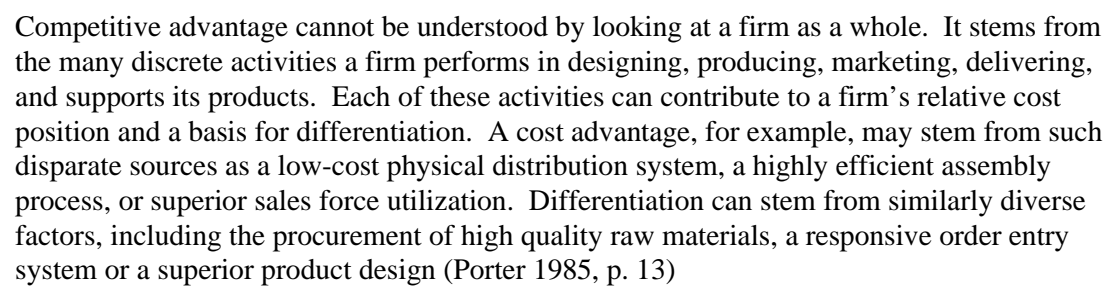

The industrial ethos has a predisposition for finding more efficient ways of getting work done. It can be dispassionate about tradition, and thus surfaces advocates and resisters. The industrial ethos occurs not just in manufacturing businesses, but also in public enterprises. It is closely related to Weber's idea of a machine bureaucracy, which served to eliminate nepotism in German civil service of the early 20th century.

A service ethos is associated with humility. Humility is the quality of having or showing a low estimate of one's own importance. It is reflected in the person providing the service recognizing the wants and needs of the customer / client / citizen above his or her own position. A service ethos does not mean a lower societal rank, as can be demonstrated in the spirit of servant leadership.

\footnotetext{
The servant-leader is servant first.... It begins with the natural feeling that one wants to serve, to serve first. Then conscious choice brings one to aspire to lead. That person is sharply different from one who is leader first, perhaps because of the need to assuage an unusual power drive or to acquire material possessions.... The leader-first and the servantfirst are two extreme types. Between them there are shadings and blends that are part of the infinite variety of human nature.

The difference manifests itself in the care taken by the servant-first to make sure that other people's highest priority needs are being served. The best test, and difficult to administer, is: Do those served grow as persons? Do they, while being served, become healthier, wiser, freer, more autonomous, more likely themselves to become servants? And, what is the effect on the least privileged in society? Will they benefit or at least not be further deprived? (Greenleaf 1977, p.13)
}

The service ethos is commonly associated with service professions such as the clergy and nursing. This does not preclude for-profit businesses placing value on serving customer and other constituents.

A service ethos in a business often espouses social and ethical features as paramount, and thus attracts individuals who share those values. The individuals choose the organization as much as the organization chooses the individuals. An individual 
who doesn't fit in with the character of an ethos-driven organization generally disassociates himself or herself within a short period of time.

4.2.3 A matrix of nine types of system models result from crossing types of resources and ethos

As a way of building systems models, the three types of resources can be matrixed with three types of ethos to produce nine system models.

Table 35-2: Nine system models

\begin{tabular}{|c|c|c|c|}
\hline - & $\begin{array}{l}\text { (a) Organic ethos: } \\
\text { local bounty }\end{array}$ & $\begin{array}{l}\text { (b) Industrial ethos: } \\
\text { machine efficiency }\end{array}$ & $\begin{array}{l}\text { (c) Service ethos: } \\
\text { humility }\end{array}$ \\
\hline $\begin{array}{l}\text { (1) Renewable re- } \\
\text { sources: } \\
\text { Cultivate and harvest }\end{array}$ & $\begin{array}{l}\text { (1a) Agroecological } \\
\text { system model } \\
\text { - (Amish) family } \\
\text { farms }\end{array}$ & $\begin{array}{l}\text { (1b) Materials refin- } \\
\text { ing system model } \\
\text { - Food processing } \\
\text { - Pharmaceuticals }\end{array}$ & $\begin{array}{l}\text { (1c) Physical well- } \\
\text { ness system model } \\
\text { - Health care }\end{array}$ \\
\hline $\begin{array}{l}\text { (2) Appropriable re- } \\
\text { sources: } \\
\text { Acquire and process }\end{array}$ & $\begin{array}{l}\text { (2a) Handcrafting } \\
\text { system model } \\
\text { - Fashion apparel }\end{array}$ & $\begin{array}{l}\text { (2b) Lean production } \\
\text { system model } \\
\text { - Petrochemicals } \\
\text { - Automobile }\end{array}$ & $\begin{array}{l}\text { (2c) Security system } \\
\text { model } \\
\text { - Insurance } \\
\text { - Banking }\end{array}$ \\
\hline $\begin{array}{l}\text { (3) Cultural re- } \\
\text { sources: } \\
\text { Affiliate and practice }\end{array}$ & $\begin{array}{l}\text { (3a) Performative ex- } \\
\text { perience system } \\
\text { model } \\
\text { - Concerts } \\
\text { - Live theatre }\end{array}$ & $\begin{array}{l}\text { (3b) Media publish- } \\
\text { ing system model } \\
\text { - News } \\
\text { - Television and } \\
\text { movies }\end{array}$ & $\begin{array}{l}\text { (3c) Intellectual de- } \\
\text { velopment system } \\
\text { model } \\
\text { - Education }\end{array}$ \\
\hline
\end{tabular}

Each of these nine system models described in Table 35-2 has unique features.

The (1a) agroecological system model, as illustrated by family farms but exemplified by the Amish, is designed around renewal resources, operating with an organic ethos. Diversity of crops, livestock and byproducts enables near selfsufficiency, with local trade supplementing family efforts.

The (1b) materials refining system model begins with similar resources to the agroecological, but takes an industrial ethos with the use of machines. Examples include food processed at superhuman speeds, or pharmaceutical development of plant and animal extracts. Corporate agribusiness also conforms to this type of system.

The (1c) physical wellness system model takes natural living beings (i.e. human beings and animals), and applies a service ethos. Health care services in the spirit of nursing are of this type.

The (2a) handcrafting system model starts with appropriable resources but applies an organic ethos. Fashion apparel, where uniqueness and custom fit are important, places a high value on craftsmanship.

The (2b) lean production system model is based on appropriable resources, and the industrial ethos is a direct descendant of the mass production style of Henry 
Ford. Petrochemical and automobile production clear follows this type of business model.

The (2c) security system model takes appropriate resources - potentially abstract, as in property rights - and applies a service ethos. Insurance means that if an insured item is lost, it can't be lost again. Banking enables funds to be channeled from those who have plenty to those who have short-term obligations to meet.

The (3a) performative experience system model is founded on cultural resources (e.g. musical scores, actors) working in an organic ethos. Concerts and live theatres are valued for their immediacy, and the immersive experience has provides benefits to "being there".

The (3b) media publishing system model takes cultural resources (e.g. concert performances), and applies an industrial ethos. Live events (e.g. news as it happens) can be reproduced at lower fidelity and bandwidth for viewers with a lesser interest in the content.

The (3c) intellectual development system model starts with cultural resources (e.g. high school graduates) and applies a service ethos. Education is delivered through pedagogy.

In contrast to the traditional three-sector categorization of agriculture, manufacturing and services, the above nine system models provide a framework through which the validity of perspectives on service systems - as well as agricultural systems and industrial systems - can be discussed. Other dimensions and categorizations could have equal validity, and friction between varied perspectives could be constructive.

\subsection{In an action science approach, this position seeks a dialectic through which mutual learning can occur}

In an appreciation of the new learning to be done on service systems, alternative positions should be considered, presented and discussed. The context for alternative positions could be driven by inquiry in various modes:

- Why? For which purposes should we develop models of service systems? Will the commonalities and distinctions between types of service systems enable crossappropriate of features as innovations?

- Where? In which circumstances and situations are more explicit or more formal models of service systems helpful? Are prior models developed in an industrial paradigm good first-order approximations?

- Who? For which professionals or domains are models of service systems useful? Will deeper inquiry introduce unnecessary confusion?

- When? How patient can we be on formalizing theoretical specifications of service systems? Will a commonsense understanding of service systems evolve naturally, or will a revolution take place?

- How? Which institutions and fields can rise to lead development of knowledge on service systems? How can questions of greater immediacy be handled, while the depth of scientific knowledge accumulates? 
Each reader of the above nine system models will have already formed an initial impression of the value of that position, and potential gaps and/or weaknesses. Dialogue within a community of inquiry on service systems can take this position as one of many starting points, in an engagement to further develop the science.

\section{Maturity in service systems will be marked with T-shaped people having deep knowledge in a type and/or a feature, and general knowledge across the varieties}

While a theory of service systems is under development, practitioners who deal with service systems every day will draw on conventional wisdom immediately at hand. Until a state of normal science has been established, concise textbooks that properly lay out the breadth of service systems will be incomplete.

To conclude this chapter, roles interested in service systems - scientists, engineers, managers and designers - are recognized. The challenge of prior knowledge from the industrial paradigm is reiterated. Finally, the maturity of the science of service systems is expressed in the development of T-shaped people with both breadth and depth in the domain.

5.1 Scientists, engineers, managers and designers should clearly see domains of knowledge as generic, or for a type or part of a service system.

No individual is omniscient. Specialization of knowledge occurs because human beings are mortal. Development of the domain of service systems amongst scientists, engineers, managers and designers is closer to infancy than to maturity. To overcome incommensurability, a common language and set of concepts is necessary.

In the mid- $20^{\text {th }}$ century, systems science emerged as a way to bridge the natural sciences, social sciences, and humanities. Systems ideas have foundations dating back to the ancient Greeks, with a universal understanding across national boundaries, cultures and languages. Systems concepts such as function, structure and process are well understood across all sciences. These foundations can be applied in development of knowledge about services in the $21^{\text {st }}$ century.

Amongst scientist, engineers, managers and designers, one of the early questions to be asked is: within what boundaries is your understanding of service systems delimited? The response could be:

- a part of the service system, e.g. the function of marketing (which may or may not coincide with a marketing department in an organizational structure);

- a type of service system, e.g. a transportation service or a professional service; or

- service systems in general, e.g. interactions between providers and clients in a variety of contexts.

Explicit specification of the domain of knowledge - as well as the domain of ignorance - can help communications and accelerate the learning on service systems. 
In the domain of information systems, much research has been conducted on capability maturity models. A similar framework - appropriate not just to practitioners but also researchers - might be helpful in the domain of service systems.

5.2 The legacy of industrial age thinking still looms large on service systems Industrialization - specifically as the introduction of technology to society - has advanced well-being in human civilization. Economies of scale improve efficiency in the production of goods, and mass distribution spreads the benefits of modern conveniences to a wider population. The improvements in productivity in industrial production have not been paralleled by improvements in productivity in services. How much of our learning in the industrial paradigm is applicable to service systems?

Developing a science of service systems may require redefinition of the types of improvement that are being sought. A service system includes both service providers and service recipients in mutual engagement. Reducing the perspective to parts of a service system - in a divide and conquer approach - won't advance our understanding in the early days of this science. Maintaining the holism in system models - requires embracing "enemies" in dialectic in the pursuit of further development (Churchman 1979).

The risk of the service sector (Wölfl 2005) - and specifically the rise of Information and Communication Technology (ICT) capital (OECD 2000) - signals that labour trained for the industrial era is being challenged to keep up with changes. Presuming that students in graduate engineering and management programs will eventually become leaders in society, they should recognize that the drivers of value creation in the next 25 years are likely to different from those in the past 25 years. As they accumulate experience in business organizations - either in for-profit or notfor-profit designations - they will shape and be shaped by the economic and technological context in their work.

5.3 When a "conventional wisdom" on service systems has been established, the breadth of depth of knowledge for $T$-shaped people can be filled out

How will we know when the science of service systems has been sufficiently developed into a normal science? One signal will be the presence of T-shaped people.

The need for T-shaped skills surfaces anywhere problem solving is required across different deep functional knowledge bases or at the juncture of such deep knowledge with an application area.... People possessing these skills are able to shape their knowledge to fit the problem at hand rather than insist that their problems appear in a particular, recognizable form. Given their wide experience in applying functional knowledge, they are capable of convergent, synergistic thinking. (Leonard-Barton 1985, p. 75)

Initial approaches to the engineering and management of service systems have built incrementally on existing disciplines. The disciplines include economics and law, operations research, industrial engineering, computer science, information systems, MBA and management consulting, management information systems and knowledge management, organizational studies and organizational learning (Spohrer, Maglio et al. 2008, pp. 6-7). Curriculum has been developed as courses inserted into existing programs (IBM 2006) and as the premise for a new program (Tukiainen 
et al. 2006). While a new science of service systems is under development, a bottom-up approach to curriculum development has been practical.

As a complementary contribution to an educational curriculum, this chapter has proposed knowledge development in a way embraces uncertainties as the science of service systems evolves. The challenge of multi-disciplinary thinking can be dissolved through a foundation in systems science.

\section{Acknowledgements}

The author appreciates ideas and feedback on the earliest drafts of this chapter from the team on "The trajectory of systems research and practice" - Allenna Leonard, Gary Metcalf, Leonie Solomons and Jennifer Wilby -- and other participants in the 2008 Fuschl Conversation hosted by the International Federation for Systems Research.

\section{References}

Ackoff, R.L. and Gharajedaghi, J. (1996). Reflections on Systems and their Models. Systems Research, 13(1), 13-23.

Ackoff, R.L. (1971). Towards a system of systems concepts. Management Science, 17(11), 661-671.

Ackoff, R.L. (1981). Creating the Corporate Future: Plan or Be Planned For, New York: John Wiley and Sons.

Ackoff, R.L. (1994). The democratic corporation, New York: Oxford University Press.

Alexander, C., Ishikawa, S. and Silverstein, M. (1977). A pattern language, New York: Oxford University Press US.

Allen, T.F.H., Tainter, J.A. and Hoekstra, T.W. (1999). Supply-side sustainability. Systems Research and Behavioral Science, 16(5), 403-427.

Allen, T.F.H., Tainter, J.A. and Hoekstra, T.W. 2003. Supply-side sustainability, New York: Columbia Univ Press.

Anderson, C. (2008). The Long Tail, New York: Hyperion.

Argyris, C. and Schön, D.A. (1974). Theory in practice: increasing professional effectiveness, San Francisco: Jossey-Bass.

Argyris, C., Putnam, R. and Smith, D.M. (1985). Action science, San Francisco: Jossey-Bass.

Arthur, W.B. (1996). Increasing returns and the new world of business. Harvard Business Review, 74(4), $100-111$.

Ashby, W.R. (1956). An introduction to cybernetics, London: Chapman \& Hall.

Atal, M. and Wokye, E. (2007). Talent Hunt: The Methodology. BusinessWeek, (D-Schools Special Report). Available at: http://www.businessweek.com/innovate/content/oct2007/id2007101_960501.htm?chan=innovation_sp ecial+report+--+d-schools_special+report+--+d-schools (Accessed November 1, 2009).

Barabási, A. (2002). Linked, Cambridge, MA: Basic Books.

Bateson, G. (1972). Steps to an ecology of mind, Northvale, NJ: Jason Aronson.

Beer, S. (1972). Brain of the firm: The managerial cybernetics of organization, New York: Wiley.

Beer, S. (1979). The heart of enterprise, New York: Wiley.

Belson, K. (2007). At IBM, a vacation anytime, or maybe none.(Electronic version). New York Times. Available at: http://www.nytimes.com/2007/08/31/nyregion/31vacation.html.

Benkler, Y. (2006). The wealth of networks: How social production transforms markets and freedom, New Haven, CT: Yale University Press.

Bourdieu, P. (1977). Outline of a theory of practice, Cambridge, UK: Cambridge University Press.

Brand, S. (1994). How buildings learn, New York: Viking. 
Checkland, P. (2005). Webs of significance: the work of Geoffrey Vickers. Systems Research and Behavioral Science, 22(4), 285-290.

Chesbrough, H. (2004). A failing grade for the innovation academy. Financial Times, 24, 43-44.

Churchman, C.W. (1971). The design of inquiring systems: basic concepts of systems and organization, Basic Books.

Churchman, C.W. (1979). The Systems Approach and its Enemies, New York: Basic Books.

Davis, M.M. and Berdrow, I. (2008). Service science: Catalyst for change in business school curriculaAuthor Bios. IBM Systems Journal, 47(1), 29-39.

de Soto, H. (2000). The Mystery of Capital: Why Capitalism Triumphs in the West and Fails Everywhere Else, New York: Basic Books.

Dreyfus, H.L. (1992). What computers still can't do: a critique of artificial reason, Cambridge, MA: MIT Press.

Eisenhardt, K.M. and Graeber, M.E. (2007). Theory Building from Cases: Opportunities and Challenges. Academy of Management Journal, 50(1), 25-32.

Emery, F.E. and Trist, E.L. (1965). The Causal Texture of Organizational Environments. Human Relations, 18(1), 21-32.

Flores, F. and Ludlow, J.J. (1980). Doing and Speaking in the Office. In Decision Support Systems: Issues and Challenges, Proceedings of an International Task Force Meeting, June 23-25, 1980. pp. 95118.

Florida, R.L. (2002). The rise of the creative class: and how it's transforming work, leisure, community and everyday life, New York: Basic Books.

Florida, R.L. (2005). The flight of the creative class, New York: HarperBusiness.

François, C. (1997). International encyclopedia of systems and cybernetics, Munich: K. G. Saur.

Friedman, V.J. (2001). Action science: Creating communities of inquiry in communities of practice. In Handbook of action research: Participative inquiry and practice. London: Sage, pp. 159-170.

Georgescu-Roegen, N. (1971). The entropy law and the economic process, Cambridge, MA: Harvard University Press.

Glushko, R.J. (2010). Seven Contexts for Service System Design. In P. P. Maglio, C. A. Kieliszewski, \& J. C. Spohrer, eds. Handbook of Service Science. Service Science: Research and Innovations in the Service Economy. Available at: http://www.springer.com/business/operations+research/book/978-1-4419-1627-3.

Greenleaf, R.K. (1977). Servant leadership, Paulist Press.

Haeckel, S.H. (1999). Adaptive Enterprise: Creating and Leading Sense-and-Respond Organizations, Boston, MA: Harvard Business School Press.

Hagel, J. and Brown, J.S. (2005). The only sustainable edge, Cambridge, MA: Harvard Business Press.

Hawk, D.L. (1999). Innovation versus environmental protection presumptions. Systemic Practice and Action Research, 12(4), 355-366.

Hedlund, G. (1986). The hypermodern MNC -- A heterarchy? Human Resource Management, 25(1), 935.

Heylighen, F. (1990). Classical and Non-classical Representations in Physics I. Cybernetics and Systems, 21(4), 423-444.

Hirschman, A.O. (1970). Exit, voice, and loyalty, Cambridge, MA: Harvard University Press.

Homer-Dixon, T. (2006). The Upside of Down, Toronto: Knopf.

IBM (2001). Service science, management \& engineering conference: Education for the 21st century. Available at: http://www.almaden.ibm.com/asr/summit/agenda.shtml (Accessed November 1, 2009).

IfM and IBM (2008). Succeeding through Service Innovation: A Service Perspective for Education, Research, Business and Government, Cambridge, UK: University of Cambridge Institute for Manufacturing. Available at: http://www.ifm.eng.cam.ac.uk/ssme/.

Ing, D. and Simmonds, I. (2002). Enabling collective knowledge work through the design of mediating spaces: A framework for systemic socio-informatic change. In Proceedings of the 46th Annual Meeting of the International Society for the Systems Sciences. Shanghai.

Ing, D. (2008). Offerings as commitments and context: Service systems from a language action perspective. In Proceedings of the 12th International Conference of the UK System Society. Oxford, UK. 
Ing, D. (2009). Envisioning Innovation In Service Systems: Induction, Abduction and Deduction. In Proceedings of the 53rd Annual Meeting of the International Society for the Systems Sciences. Brisbane, Australia.

Ing, D., Takala, M. and Simmonds, I. (2003). Anticipating organizational competences for development through the disclosing of ignorance. In Proceedings of the 47th Annual Meeting of the International Society for the System Sciences. Hersonissos, Crete.

Jackson, M.C. (2000). Systems approaches to management, New York: Kluwer.

Jackson, W. (1987). Altars of Unhewn Stone: Science and the Earth, San Francisco: North Point Press.

Jacobs, J. (1992). Systems of survival: a dialogue on the moral foundations of commerce and politics, New York: Random House.

Jacobs, J. (2001). The Nature of Economies, Toronto: Vintage.

Jamshidi, M. (2009). System of systems engineering: innovations for the 21st century. In System of systems engineering: innovations for the 21st century. Hoboken, NJ: Wiley.

Katz, D. and Kahn, R.L. (1978). The social psychology of organizations 2nd ed., New York: Wiley.

Kuhn, T.S. (1967). The structure of scientific revolutions, Chicago: University of Chicago Press.

Leonard-Barton, D. (1995). Wellsprings of knowledge: Building and sustaining the sources of innovation, Cambridge, MA: Harvard Business Press.

Levin, M. and Greenwood, D. (2001). Pragmatic Action Research and the Struggle to Transform Universities into Learning Communities. In Handbook of action research: Participative inquiry and practice. London: Sage.

McIntyre, J. (2004). Facilitating critical systemic praxis (CSP) by means of experiential learning and conceptual tools. Systems Research and Behavioral Science, 21(1), 37-61.

Miles, R.E. et al. (1997). Organizing in the Knowledge Age: Anticipating the Cellular Form. The Academy of Management Executive (1993), 11(4), 7-24.

Miller, J.G. (1978). Living systems, New York: McGraw-Hill.

Mitroff, I.I. and Linstone, H.A. (1993). The unbounded mind: Breaking the chains of traditional business thinking, New York: Oxford University Press.

Mitroff, I.I. (1998). Smart Thinking for Crazy Times: The Art of Solving the Right Problems. San Francisco: Berrett-Koehler.

Normann, R. and Ramirez, R. (1994). From value chain to value constellation: designing interactive strategy, Chichester, England: Wiley.

Normann, R. (2001). Reframing business, New York: Wiley.

Odum, E.P. (1983). Basic ecology, Philadelphia: Saunders College Publishing.

Odum, H.T. (2007). Environment, power, and society for the twenty-first century, New York: Columbia University Press.

OECD (2000). A New Economy? The Changing Role of Innovation and Information Technology in Growth. Available at: http://www.oecd.org/document/62/0,3343,en_2649_34273_2675198_1_1_1_1,00.html.

OECD (2007). OECD Science, Technology and Industry Scoreboard 2007: Innovation and Performance in the Global Economy. Available at: http://www.oecd.org/document/10/0,3343,en_2649_33703_39493962_1_1_1_1,00.html.

Page, S.E. (2008). The Difference: How the power of diversity creates better groups, firms, schools, and societies., Princeton, NJ: Princeton University Press.

Parhankangas, A. et al. (2005). Negotiated order and network form organizations. Systems Research and Behavioral Science, 22(5), 431-452.

Perlmutter, H.V. and Heenan, D.A. (1979). Multinational organization development, Reading, MA: Addison-Wesley.

Perrow, C. (1984). Normal accidents, New York: Basic Books.

Porter, M.E. (1985). Competitive advantage: Creating and sustaining superior performance, New York: Free Press.

Ramírez, R. and Wallin, J. (2000). Prime movers: define your business or have someone define it against you, Chichester, England: Wiley.

Ravetz, J.R. (1971). Scientific knowledge and its social problems, London: Oxford University Press.

Ravetz, J.R. (2004). The post-normal science of precaution. Futures, 36(3), 347-357. 
Raymond, E.S. (2000). The Cathedral and the Bazaar. Available at: http://www.catb.org/ esr/writings/cathedral-bazaar/cathedral-bazaar/ (Accessed November 1, 2009).

Rosen, R. (1985). Anticipatory systems: Philosophical, mathematical \& methodological foundations, Elmsford, NY: Pergamon Press.

Rowland, G. (2004). Designing with a homeopoietic ethic for organizational change. Systems Research and Behavioral Science, 21(3), 219-226.

Schön, D.A. (1983). The reflective practitioner, Basic Books.

Senge, P.M. (1990). The fifth discipline, New York: Doubleday/Currency.

Spohrer, J. et al. (2007). Steps Toward a Science of Service Systems. Computer, 40(1), 71-77.

Spohrer, J. et al. (2008). The service system is the basic abstraction of service science. In Proceedings of the 41st Annual Hawaii International Conference on System Sciences. HICSS. p. 104.

Strauss, A.L. (1978). Negotiations : Varieties, contexts, processes, and social order, San Francisco: Jossey-Bass.

Swedberg, R. (2003). Principles of economic sociology, Princeton, NJ: Princeton University Press.

Trist, E.L. and Bamforth, K.W. (1951). Some Social and Psychological Consequences of the Longwall Method of Coal-Getting: An Examination of the Psychological Situation and Defences of a Work Group in Relation to the Social Structure and Technological Content of the Work System. Human relations, 4(1), 3.

Trist, E.L., Murray, H. and Emery, F.E. (1997). The Social Engagement of Social Science: The socioecological perspective, University of Pennsylvania Press.

Tukiainen, T., Takala, M. and Ing, D. (2006). Master's program for service management at Helsinki Polytechnic Stadia. In Service Science, Management and Education Conference: Education for the 21st Century. Palisades, NY.

Wallin, J. (2006). Business orchestration: Strategic leadership in the era of digital convergence, Chichester, England: Wiley.

Walton, D.C. (2004). Designing within: Dr Bela H. Banathy's contributions to the self-organization of public discourse. Systems Research and Behavioral Science, 21(3), 281-293.

Wenger, E. (1999). Communities of practice, Cambridge, UK: Cambridge University Press.

Winograd, T. and Flores, F. (1986). Understanding Computers and Cognition: A New Foundation for Design, Norwood, NJ: Ablex.

Witte, M.H., Kerwin, A. and Witte, C.L. (1998). Curriculum on medical and other ignorance: shifting paradigms on learning and discovery. Memory distortions and their prevention, 125-156.

Wölfl, A. (2005). The Service Economy in OECD Countries, Organization for Economic Co-operation and Development. Available at:

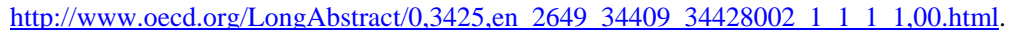




\title{
Biographical Sketch
}

David Ing is a marketing scientist and business architect with a 25-year career at IBM. He is completing his Ph.D. in Industrial Management at Aalto University, with prior degrees from the Kellogg School of Management and the University of Toronto. In professional activities, he has served a variety of roles for the International Society for the Systems Sciences, currently as the Vice-President of Research and Publications. David resides in Toronto, Canada, and is an active blogger at http://coevolving.com.

\section{Contact information}

\author{
David Ing \\ Marketing Scientist and Business Architect \\ IBM Canada Ltd. \\ 3600 Steeles Avenue East \\ Markham, ON Canada L3R $9 Z 7$ \\ +1-416-478-8086 \\ daviding@ca.ibm.com
}

